\title{
Circumcision and periurethral carriage of Proteus mirabilis in boys
}

\author{
J GLENNON,**P J RYAN,* C T KEANE, $\dagger$ AND J P R REES* \\ ${ }^{*}$ National Children's Hospital and †Department of Clinical Microbiology (Trinity College, Dublin), \\ St James's Hospital, Dublin
}

SUMmaRY Swabs were taken for culture from the periurethral area and urethral meatus in 124 uncircumcised and 60 circumcised boys. Proteus mirabilis was grown from $28(22 \cdot 6 \%)$ swabs from uncircumcised boys and from only one $(1.7 \%)$ swab from circumcised boys. This supports the idea that the prepuce may be the source of proteus urinary tract infection.

Differences in the pattern of bacteria causing urinary tract infection are age and sex related. Proteus mirabilis features more prominently as a urinary pathogen in boys than girls. ${ }^{1}$ It is unclear why this difference occurs. Periurethral colonisation may be an important event as a prelude to ascending infection through the urethra. ${ }^{2}$ Furthermore one study has shown that the difference in bacterial aetiology with age and sex in children with urinary tract infection correlates with a similar variation in the periurethral flora. ${ }^{3}$

Table 1 Comparison of organisms cultured from uncircumcised and circumcised boys

\begin{tabular}{lcc}
\hline Organism & $\begin{array}{l}\text { No }(\%) \text { of } \\
\text { uncircumcised } \\
\text { boys }(n=124)\end{array}$ & $\begin{array}{l}\text { No }(\%) \text { of } \\
\text { circumcised } \\
\text { boys }(n=60)\end{array}$ \\
\hline Proteus mirabilis & $28(22 \cdot 6)$ & $1(1 \cdot 7)$ \\
Streptococci & $6(4 \cdot 8)$ & $7(11 \cdot 7)$ \\
Escherichia coli & $5(4 \cdot 0)$ & 0 \\
Staphylococcus aureus & $1(0 \cdot 8)$ & $1(1 \cdot 7)$ \\
Bacteroides & $1(0 \cdot 8)$ & 0 \\
Commensals/no growth & $87(70 \cdot 2)$ & $51(85 \cdot 0)$ \\
\hline
\end{tabular}

There is little information on the periurethral flora, particularly proteus carriage of circumcised boys, perhaps due to the difficulty in obtaining sufficient numbers of subjects. We sampled the periurethral flora in uncircumcised and circumcised normal boys.

\section{Patients and methods}

The patients sampled in the survey were either inpatients or outpatients of the National Children's Hospital who had conditions unrelated to the urinary tract and no history of urinary tract disease. Their ages ranged from 6 weeks to 14 years. There were 124 uncircumcised boys with a mean age of $4 \cdot 8$ years and 60 circumcised boys with a mean age of 6.7 years. None were receiving or had recently received an antibiotic and none were on any immunosuppressive treatment.

Sampling was as follows: in the uncircumcised boys the preputial sac was sampled. In the circumcised a swab was pressed against the periurethral area and the urethral meatus. In both cases a moistened swab was used. The swab was then inserted into Amies transport media and sent promptly to the laboratory where blood agar, McConkey's agar, and neomycin blood agar were inoculated and incubated for 48 hours in aerobic and anaerobic conditions and the isolates identified and recorded.

\section{Results}

The results are shown in table 1 . They show a significantly higher rate of $P$ mirabilis in uncircum-

Table 2 Isolation of organisms from uncircumcised boys in different age groups

\begin{tabular}{|c|c|c|c|}
\hline \multirow[t]{2}{*}{ Organism } & \multicolumn{3}{|c|}{ No $(\%)$ of boys in age groups } \\
\hline & $\begin{array}{l}6 \text { weeks-<1 year } \\
(n=27)\end{array}$ & $\begin{array}{l}1-<5 \text { years } \\
(n=32)\end{array}$ & $\begin{array}{l}5-14 \text { years } \\
(n=65)\end{array}$ \\
\hline Proteus mirabilis & $12(44 \cdot 4)$ & $8(25 \cdot 0)$ & $8(12 \cdot 3)$ \\
\hline Streptococci & $1(3 \cdot 7)$ & 0 & $5(7 \cdot 7)$ \\
\hline Escherichia coli & $4(14 \cdot 8)$ & 0 & $1(1 \cdot 5)$ \\
\hline Staphylococcus aureus & $1(3 \cdot 7)$ & 0 & 0 \\
\hline Bacteroides & 0 & 0 & $1(1 \cdot 5)$ \\
\hline Commensals/no growth & $12(44 \cdot 4)$ & $24(75 \cdot 0)$ & $51(78 \cdot 5)$ \\
\hline
\end{tabular}


cised boys $(22 \cdot 6 \%)$ compared with circumcised boys $(1.7 \%)(\mathrm{p}<0.001)$.

Table 2 shows a breakdown of the figures according to different age groups. The figures sometimes add up to more than the total number of patients as in some cases a mixed growth was reported-for example, proteus and streptococci. There was a decreasing incidence of proteus isolation with age in uncircumcised boys ranging from $44.4 \%$ in infants, $25 \%$ in the $1-5$ year olds, to $12.3 \%$ in school age children. These differences are significant $(\mathrm{p}<0.001)$.

Growths of proteus in uncircumcised boys were reported as heavy in seven patients, moderate in 11 , and light in 10 . The heavy growths occurred only in infants and preschool children.

The one swab from a circumcised boy to grow proteus had a mixed culture with only a light growth of proteus. As so few circumcised boys had positive cultures, analysis by age group was not possible.

\section{Discussion}

Hallett et al showed that proteus was a common cause of urinary tract infection in boys and was responsible for $67 \%$ of infections in their series. ${ }^{1}$ They produced evidence suggesting that the organism might originate from the prepuce or urethra.

The same authors isolated proteus from preputial swabs in $82 \%$ of boys who had had urinary tract infections; they found proteus in only $10 \%$ of a control group of boys and all of these were under 6 years of age. As mentioned above we also isolated proteus much more commonly in children under 5 years old and only obtained heavy growths of the organism in this age group.

Hallett et al also showed that the pattern of infecting organisms changes at puberty and that Escherichia coli becomes the predominant organism in adult males, ${ }^{1}$ although over the age of 60 years proteus again becomes a frequent pathogen suggesting a relation to prostatic secretion.

Clearly simple carriage in the preputial sac does not always lead to urinary tract infection.

In patients with urinary tract abnormalities and those who get repeated attacks of urinary tract infection $P$ mirabilis is an important pathogen frequently affecting the upper urinary tract. No 'clear' virulence factor has been shown to be important. There is no relation between the organism's adhesiveness, origin, and its association with urinary tract infection. ${ }^{2}$ It would be of interest, however, to study preputial strains in subjects who develop urinary tract infections and compare them with simple carriers.

A recent study in infants by Wiswell et al showed that the declining frequency of routine circumcision was accompanied by an increased incidence of urinary tract infections. ${ }^{4}$ They considered only infants and did not record any causative organisms. ${ }^{4}$

It would be difficult to justify routine circumcision. If one regards the incidence of urinary tract infection in boys of all ages as $0.9 \%$, circumcision might protect four or five boys per 1000 from proteus species. This hardly seems justifiable bearing in mind that the operation is not without risk. Alternatively some form of foreskin cleansing might be an alternative approach to prophylaxis, but it is rarely practised. ${ }^{5}$

Ghazalis et al have shown the close relation between urinary calculi and proteus infection so these infections must be taken seriously. ${ }^{6}$

We consider that this study strongly points to the preputial sac as an important reservoir of $P$ mirabilis in the age group investigated. Study of the virulence factors of different strains may give an indication of those that will invade the urinary tract.

\section{References}

1 Hallett RJ, Peade L, Maskell R. Urinary infection in boys. Lancet 1976;ii:1107-10.

2 Adegbola RA, Old BC, Senior BW. The adhesions and fimbriae of Proteus mirabilis strains associated with high and low affinity for the urinary tract. J Med Microbiol 1983;16:427-31.

${ }^{3}$ Bollgren I, Windberg J. The periurethral acrobic bacterial flora in healthy boys and girls. Acta Paediatr Scand 1976;65:74-80.

${ }^{4}$ Wiswell TE, Smith FR, Bass JW. Decreased incidence of urinary tract infection in circumcised male infants. Pediatrics 1985;75:901-3.

5 Malleson P, Wiswell TE. Prepuce care. Pediatrics 1986;77:265.

6 Ghazalis S, Barratt TM, Williams DI. Childhood urolithiasis in Britain. Arch Dis Child 1973;48:291-5.

Correspondence to Dr J P R Rees, National Children's Hospital, Harcourt Street, Dublin 2, Eire.

Accepted 7 December 1987 